\title{
A CRIMINOLOGIA DE CLÓVIS BEVILAQUA
}

\author{
Laertes de Macedo Munhoz \\ Professor Catedrático da Faculdade de \\ Direito da Universidade do Paraná
}

No volume em que reuniu, nos idos de 1896, os artigos desentranhados do Archivo Brasileiro, da Revista do Norte, da Revista Academica, da Revista Contemporanea e outras mais, do fim do século 19, assim escrevia, numa passagem do seu Prefácio, o então jovem jurista CLÓVIS BEVILAQUA: "quanto à parte criminológica, também ligeira, vale por notas de um excursionista apaixonado pelas paisagens por onde passa ao correr da locomotiva, ou por silhouttes empastados, que dão os contornos dos objetos, mas não lhes indicam as nuanças do colorido nem as ondulações do relevo".

Era aquela uma época em que o direito penal recebia, muito mais em cheio do que o direito privado, as incursões estrepitosas dos novos conceitos da ciência.

A antropologia de Lombroso e a sociologia de Ferri, pretendendo dar por terra com o romantismo de Carrara e o liberalismo de Carmignani, abriam caminho para as transações ecléticas de Tarde e Von Liszt, as quais, descortinando horizontes mais amplos, porque muito mais tolerantes, senão mesmo mais humanos, posto que mais condizentes com a realidade da vida e suas necessidades político-sociais, haveriam de revelar a compatibilidade de métodos que pareciam irreconciliáveis na obstinação dos postulados rígidos das escolas.

O gênio de Tobias Barreto, a êsse tempo, pregava, no Recife, a falta de sentido ou significação para a velha inimi- 
zade entre o filosófico e o histórico, e apontava à ciência do direito penal, que como tôdas as ciências deve ter um método para o seu estudo e pesquisa, o chamado método históricofilosófico, dêle apregoando as excelências para se poder chegar a conhecer "os verdadeiros fatores das leis penais", e por não achá-lo incompatível com uma parte dogmática e uma parte crítica no estudo do direito criminal.

Era mais o filósofo do que o jurista a penetrar na metafísica das teorias, mais ou menos nebulosas, com que a grande pátria dos nebelungs empolgava o eminente mestre da escola do Recife, a cuja sombra se haveriam de acolher as mais formosas culturas humanísticas da época, tão devotas do estudo, quanto do deslinde das teorias que surgiam no Velho Mundo.

O direito penal é talvez tão velho quanto o direito civil, mas tem sôbre êste a supremacia de um encanto enciclopédico que o torna mais sedutor ao espírito de pesquisa, à leitura, à análise, à meditação da própria história da humanidade. A temática penalista é em tudo mais atraente. Todos os seus problemas se equacionam à base do homem como ser vivo. $\mathrm{O}$ crime é exclusivamente ato humano que abala e emociona a sociedade, mas que desafia os pontos de vista das ciências que dêle se ocupam e das suas relações entre si. $\mathrm{E}$ essas ciências, sem deixarem de tocar na filosofia, na história, na psicologia, na ética, na biologia, na antropologia, são, sobretudo, o direito penal, a política criminal e a criminologia. Esta, como ciência especulativa, ao contrário do direito penal e da política criminal, como ciências práticas, indiscutivelmente cabe mais ao sábio do que ao jurisconsulto.

Daí a explicação lógica e natural da incursão do gênio de CLOVIS BEVILAQUA no campo da criminologia, não como simples diletante, mas como investigador e estudioso dos seus fenômenos, sem porém, abdicar da sua formação de jurista afeito às ciências práticas dos jurisconsultos, o que o levaria a ponderar, conforme bem observou o Dr. José Higino Duarte Pereira no prefácio de tradutor do Lehrbuch de von Liszt, "que ainda quando tôdas as ciências naturais projetassem tôda a luz sôbre o fenômeno do crime, faltaria alguma coisa para bem o compreendermos" - "o fim prático, são agora palavras de CLóVIS, o fim que determinou a necessidade das in- 
dagações sôbre a origem, a natureza, as formas e o alcance de fenômeno criminológico, se não desnublaria: será preciso que depois de tôdas essas ciências, aproveitando certamente os dados por elas fornecidos, fale o direito", o direito como arte, como ciência, como filosofia.

O conceito, como se vê, é de lapidar exatidão. Ninguém, hoje, ousará negar, ainda mesmo nos regimes autoritários, que tanto se açodaram a abraçar o contributo das ciências sociais e naturais do positivismo do século 19 para a solução das questões criminológicas, que a supremacia da palavra, no sentido dessas soluções, cabe ao direito, ou mais precisamente à ciência do direito, na sua tripartição em dogmática jurídica, história do direito e filosofia do direito. Sobretudo à dogmática jurídica, isto é, a parte da ciência do direito que, segundo Roussel, contestado por Pedro Lessa, tem por objeto o direito positivo, estudado em sua formação, interpretação, aplicação e execução, o que representaria o absurdo de incluir a dogmática jurídica entre as ciências "ou da sua qualificação como ramo da ciência do direito, absurdo que, evidentemente, não mereceu o sufrágio de CLóVIS BEVILAQUA, que, dando a palavra ao direito para o fim prático da solução das questões criminológicas, emprestava à dogmática o seu verdadeiro sentido, circunscrevendo-a à tarefa de reconstruir o pensamento do legislador, para bem aplicar a lei fundada em bases científicas, ou usando da lição clássica de Pedro Lessa, fundada "nas ciências que hão de subministrar ao júrista os subsídios necessários à formação de uma teoria verdadeira acêrca da limitação das atividades, condição sine qua non da existência social".

Daí porque ouso afirmar que CLÓVIS BEVILAQUA como criminalista ou penalista ou criminólogo, foi, antes de tudo, um jurista. Os seus estudos, as suas indagações, as suas pesquisas, por mais que penetrassem "nas misteriosas regiões sagradas das ciências naturais", davam, como remate, ao direito a solução final, porque, conforme as suas próprias palavras, "sòmente êle poderá efetuar a convergência dos pontos de vista, sòmente êle poderá dar um remate e o acabamento natural aos processos de indução iniciados por outras quaisquer disciplinas em relação ao crime, porque é êsse um fenômeno de ordem sociológica e da espécie jurídica, muito 
embora suas raízes se prolonguem e penetrem nos domínios distantes da psicologia e da biologia, muito embora outras disciplinas reclamem a competência para o esclarecimento de suas condições primárias".

$\mathrm{E}$, nesta mesma ordem de idéias, acrescenta:- "Aceitemos, os juristas, tôdas as informações, quaisquer que sejam as suas fontes, contanto que sejam sinceras e provadas, peçamos documentos a todos os sistemas, a todos os métodos empregados para dissecar, explanar e classificar o crime e o. criminoso; mas, neste conflito de jurisdição, não cedamos uma linha, porque iríamos assim amputar uma das mais belas porções da jurisprudência". "E nem é sòmente no estudar o crime e o criminoso que o direito pede auxílio a outros domínios da ciência. As diversas disciplinas em que o saber humano se divide formam um consenso entretercido por interdependências perfeitamente assinaláveis".

Poderíamos alongar considerações sôbre êste tema, evidentemente de relevante importância jurídico-penal. Mas para acentuar o caráter eminentemente jurídico da disciplina penal, que hoje é um canon irretorquível, bastam as palavras esclarecedoras do Mestre, cujo centenário de seu nascimento comemoramos: "a idéia do crime, disse êle, constitui uma oppositio contraria à idéia do direito. Se existe crime é porque existe direito, e a idéia subversiva de um é como que a sombra da idéia construtora do outro. Nasceram conjunta e simultâneamente, têm vindo a rolar engalfinhados um ao outro, através das idades, transformando-se, muitas vêzes, em repercussão recíproca, e, se o direito já conseguiu dilatar consideràvelmente seu campo de ação, não expulsou da sociedade, nem jamais expulsará o elemento desorganizador que nela fermenta". "Dessa conjunção lógica, histórica, social e psíquica, resulta que, para determinar a noção do crime se tem de prèviamente firmar a noção de direito; para conhecer como a ação corrosiva atua sôbre a organização social, se tem de examinar, ao mesmo tempo, como o direito lutou com êle, até que ponto foi vitorioso e porque não conseguiu mais; para estabelecer as transmutações sucessivas por que têm passado as formas criminais, forçoso será estudar as transformações correspondentes das formas jurídicas".

Faz a apologia da criminologia como sendo "a ciência que 
recorre a todos os elementos da história, da estatística da psicologia, da biologia, da etnologia e de quaisquer outras disciplinas que lhe possam fornecer luzes e documentos, em cuja esfera também se inclui a filosofia do direito, sem ver razão plausível para deslocá-la da jurisprudência".

Daí a consequiência lógica de sua crítica à escola antropológica, na qual reconhecia, é verdade, e nem o seu alto espírito filosófico e científico poderia deixar de assim proceder, "méritos incontáveis" e grandes serviços prestados à ciência, os quais, segundo o pensamento de Alimena, enunciado em 1894, teriam sido êstes principalmente: "o fundar-se sôbre a negação do livre arbítrio; o ter insistido sôbre a defesa social; o ter estudado o delinqüente e o delito; o ter dado lugar mais largo à prevenção. Não obstante tais méritos, que CLÓVIS endossa plenamente, forçoso é registrar, como faz o professor napolitano citado por êle, que a escola antropológica deixou-se levar muito pela teoria do organismo social, esquecendo que, mesmo para Spencer, há organismos contínuos, que são os animais, e organismos discretos que são os sociais, os chamados superorganismos. A conseqüência natural dessa exageração foi essa extraordinária e chocante simplificação da reação penal, pelos processos de pura eliminação e de rigor draconiano, a que conduziam os princípios da lógica".

Era, como se vê, o brado de alerta do próprio pensamento brasileiro contra a agressão científica da Escola Positiva, contra a primeira investida às instituições liberais do Direito Penal, que a propósito de combater o liberalismo da Escola Clássica, por vêzes taxada de romântica e teórica, transformando as idéias de Lombroso em uma espécie de sociologia, abriria caminho fácil para o direito penal autoritário.

É aceitável a observação de nosso Mestre Luís Jimenez de Asua, quando adverte que se seguirmos os seus passos não podemos nos assombrar de que tenha sido o positivismo, germinado das idéias lombrosianas, o inspirador, mais ou menos incorreto, de muita coisa que os fascistas e nazistas introduziram em sua legislação penal.

Aí se refletiu, com grande intensidade, a concepção positivista de Garofalo, que, por considerar o delinqüente como uma fera, vai ao extremo de repudiar a sua condição de nos- 
so semelhante. E, assim, dentro dessa concepção, verdadeiramente brutal, de Garofalo, que teve e infelizmente ainda tem seguidores, não haveria problema ou problemas a discutir, dado que o delinqüente, por não ser nosso semelhante, senão uma variedade do genus homo, não teria por que ser polìticamente protegido. Tudo se resolveria na simplicidade cruel da pena eliminatória.

Dentro dessa concepção do velho Garofalo, nem haveria lugar para o princípio eminentemente liberal do nullum crimen nulla poena sine lege, porque para o revide contra os ataques da bêsta selvagem não há, evidentemente, necessidade de estabelecer limitação política à atividade punitiva do Estado.

Contra tantas deformações jurídicas, CLOVIS desfraldou conscientemente a bandeira de Carnevale, associando-se à terza scuola di diritto penale, não por uma simples curiosidade turística pelas nuances de uma paisagem nova, mas pelo imperativo de uma vocação filosófica a serviço do direito em sua magna puridade. Era a afirmação do direito penal, não mais como expressão romântica do classicismo, nem como decorrência lógica da agressão do positivismo, mas como a disciplina científica e política destinada à proteção do bem jurídico.

A influência positivista, repudiando os mandamentos do Aufklaerung levaria a Alemanha a pisotear o fundamento filosófico de Kant sôbre a liberdade: "uma imagem primitiva da vida", atributo misterioso e fecundo da personalidade sob o pálio compreensivo e categórico das leis da natureza, poderosa aspiração que amplia indefinidamente o horizonte. E o seu Código Penal de 1933, abeberado nos mais conspícuos princípios do nacional-socialismo, trazia a marca indispensável para a sobrevivência da ditadura nazista, criando um direito penal contra a vontade criminosa (Willenstrafrecht) sem cingir sua atenção aos atos exteriores do comêço de execução; criando um direito penal de raça, aplicado à defesa dos interêsses vitais do povo alemão (Rassenstrafrecht): um direito penal que passa a consagrar, como finalidade diretiva, a consciência esclarecida do povo alemão, ou mais ao pé da letra, "a sã consciência do povo alemão" (Gesunde Volksanschauung). 
A Itália, a velha e luminosa Itália, "progenitora das leis", "matriz da cultura", "mãe das artes", havia sido imposto, em 1930, um direito penal colateral do regime. O Código, então revogado, que vinha de 1889 , que tinha sido inspirado pelo neo-clássico Francisco Carrara, que tinha sido redigido pelo idealismo de Zanardelli em nome da monarquia parlamentar, passaria para a história como um diploma legal progressista, humanitário, liberal. O Código que vinha substituí-lo era apenas um Código autoritário. Era um Código de caráter puramente político, embora a sua originalidade científica, especìficamente italiana. Mas como um nouveau venu do imperialismo, como disse Donnedieu de Vabres, era apenas uma expressão da doutrina mussoliniana que, saltando sôbre os séculos, procurava imitar os Imperadores romanos.

Mas se foi assim na Itália e na Alemanha, mais ainda se acentuou sob o signo do positivismo a criminologia soviética, que culminou por consertar o conceito da criminalidade, como fenômeno fisio-psicológico, no empenho de rejuvenescer a doutrina de Lombroso. E a adesão, quase completa, ao projeto de Ferri, com a construção de uma legalidade revolucionária, mas que tinha suas raízes no velho e rude propósito, animado do sentimento de vingança social, que vinha do Código de 1832, robustecido pela escola do materialismo histórico. Aí, as causas da delinqüência como que se restringem à riqueza e ào egoísmo de uns, à miséria e à cupidez de outros. E a codificação de um direito destinado a alimentar a luta de classes, como meio de atingir ao fim almejado, ou seja, uma sociedade sem classes. Por isso, a legislação revolucionária soviética, investindo contra o pensamento liberal do direito penal, não é mais do que uma organização da violência. Surge, daí, de maneira ainda mais arrogante do que na Alemanha, o desconhecimento integral do princípio da anterioridade para a conceituação formal do delito. É o desprêzo insolente ao princípio da tipificação objetiva, que passa a subordinar-se ao princípio opressor da perigosidade sem delito. E a adoção, como na Itália e na Alemanha, da pena de morte, em contraposição ao sentimento burguês de fraternidade proclamada pela revolução francesa.

Parece que, diante dessa crise do direito penal, que o século 20 haveria de assistir e sofrer, tiveram um dom profético, 
senão uma invencível inspiração vocacional, os contornos da criminologia de CLÓVIS BEVILAQUA, ao subordinar as ciências que informam a política criminal ao império do direito, no seu tríplice aspecto, como arte, como ciência e como filosofia, com o que se aproximava, quase por instinto, da lição de Von Liszt, segundo a qual "o direito penal e a política criminal são dois ramos do mesmo tronco, que se tocam, se cruzam e se frutificam; sem esta relação de mútua dependência, desnaturam-se e é inevitável a decadência do direito penal", até porque, em última análise, o crime não é apenas uma idéia, "mas um fato do mundo dos sentidos" e "a pena não existe por amor dela mesma".

Está bem claro que na mediocridade dêste ligeiro estudo sôbre um aspecto das atividades científicas e jurídicas do insígne brasileiro a que a posteridade ficou devendo o grande monumento do nosso Código Civil, que por mais envelhecido no tempo, será sempre um paradigma de sabedoria e sistematização, não há a pretensão de enaltecer uma especialidade que CLÓVIS BEVILAQUA não elegeu com maior ânimo, nem com mais curada devoção. O cultivo do direito penal foi, nêle, mais uma decorrência da sua formação filosófica de sábio atento e estudioso dos grandes e vexatórios problemas sociais. Não foi um penalista no sentido técnico e didático. Mas também não foi aquêle excursionista apaixonado pelas paisagens por onde teria passado ao correr da locomotiva. Foi, isto sim, o espírito penetrante da universalidade jurídica, o filósofo debruçado sôbre o grande estuário das doutrinas revôltas, si bem que, como acentuou o Prof. Vieira Neto, "tivesse tido vida de rio tranquilo", foi bem "um Nilo paciente a arrecadar a vaza, para fertilizar e construir".

No prólogo de ur dos livros de Alípio Silveira - "A interpretação das leis e os regimes políticos" - escreve Jimenez de Asua, o mais fecundo penalista de nossos tempos: "En el prologo de outro libro de Alipio Silveira ha destacado Clovis Bevilaqua el metodo y la originalida del autor, y lo que aquel dice hace autoridad en el campo de los estudos criminologicos, yá que Bevilaqua es otro de los grandes juristas brasileños, y, sin disputa, el criminologo más lleno de espirito creador".

Não desconhecia Asua, ao escrever essas linhas, a estatura de TOBIAS BARRETO, JOÃO VIEIRA, JOSÉ HIGINO, 
VIRGILIO DE SÁ PEREIRA, para só falar de alguns dos cultores mais ativos do direito penal, dos muitos pensadores, juristas, filósofos, poetas e críticos que abrilhantam e imortalizam a história da Faculdade de Direito de Recife, na qual a labuta do pensamento, o choque das idéias, a pesquisa dos princípios, o entusiasmo criador, chegaram a formar escola, precisamente a chamada Escola do Recife, que no dizer do próprio CLÓVIS, "não era um rígido conjunto de princípios, uma sistematização definitiva de idéas, mas sim uma orientação filosófica progressiva, que não impedia a cada um investigar por sua conta, e ter idéas próprias, contanto que norteadas científicamente".

Essse movimento teve, indiscutivelmente, três vultos inconfundíveis, como assinala Hermes Lima, Tobias, Sílvio Romero e CLÓVIS BEVILAQUA, - mas si há restrições ao primeiro e ao segundo, a CLÓVIS cabe a glória de haver construído "uma obra mais solida e organizada, um pensamento filosófico de maior seqüência, podendo-se, por isso mesmo, afirmar que foi êle quem melhor teve a visão universal dos problemas de alta indagação, estruturando-os de acôrdo com aquelas idéas que lhe pareceram mais verdadeiras", como bem observa Alcantara Nogueira no seu recente livro "O pensamento filosófico de CLÓVIS BEVILAQUA", no qual se lê ainda mais esta referência apologética à probidade científica do insígne mestre: "A sua posição, qualquer que tenha sido o setor do seu interêsse, apresenta-se com caracteres inconfundíveis, onde o pensador está atento para considerar os problemas em todos os seus ângulos possíveis, discutindo-os sem revelar de pronto o seu julgamento. Porque êste aparece paulatinamente através do debate, decidido nas conclusões, mas nunca com o entusiasmo messiânico dos que pretendem esgotar a verdade".

$E$, pois, justo o registro do mesmo autor, no sentido de evidenciar que CLÓVIS encarnou, mais do que todos que atuaram no movimento, o pensamento cético e agnóstico, construído em bases de uma atitude positiva e, notadamente evolucionista, comprometida com o spencerianismo. Dentro dessa orientação, nesse período, nenhum outro estudioso da Filosofia no Brasil o ultrapassou". Assim, "é justo e exato reconhecer que CLÓVIS BEVILAQUA foi o pensador de quali- 
dades mais expressivas da Escola do Recife". E que foi "de uma fidelidade sem vacilações aos princípios que adotou" e, por isso, "CLÓVIS constitui um exemplo completo de convicção ideológica, que poderá servir de roteiro aos que desejarem fazer do espírito um instrumento aplicado à libertação do pensamento e à glória da verdade, que não seja ditada por crenças ou imposta sem discussão".

$\mathrm{E}$ quem assim se conduziu na longa trajetória da sua vida de filósofo e de jurista, não deixaria de emprestar, como emprestou, ao campo do direito penal, sobretudo da criminologia, a coerência sobranceira do seu pensamento, da sua cultura, da sua vocação, podendo, com justeza, ser incluído entre os pioneiros dos princípios liberais da penalística moderna, cujo colapso, na Alemanha e na Itália, foi apenas uma crise acidental, a que as idéias de liberdade, fraternidade e igualdade haveriam de sufocar quase no nascedouro, e que na Rússia soviética é uma excepção prestes a se extinguir, pelo impacto verdadeiramente atômico do pensamento universal, que, hoje, mais do que em qualquer outro tempo, se recusa avalisar as deformações da ciência e as contrafações autoritárias do direito penal.

Contra êsses distúrbios da opressão, CLÓVIS foi um exemplo vivo, constante, inalterável. Viveu uma vida de apóstolo. E sempre que foi convocado para colaborar na felicidade da coisa pública ou na tarefa de defesa e preservação das instituições cívicas e jurídicas da pátria, jamais deixou o apêlo de receber a pronta acolhida, jamais o encontrou fatigado, negligente, sequer indiferente. Dava de si o máximo que podia dar: a dedicação quase abnegada de um caráter impoluto, e a contribuição segura de uma inteligência esclarecida e culta, sem deslises, sem incoerências, sem ressalvas mentais, sem ambição material, completamente despida de qualquer setarismo. E, aí, sábio e apóstolo, era também quase um santo.

Nas inúmeras tentativas para a elaboração de uma meIhor codificação das leis penais militares, aspiração que o Império herdou à República, a presença de CLóVIS se tornou indispensável. O seu projeto de 1912, elaborado em poucos dias, a que êle mesmo denominou Esboço do Código Penal da Armada, representou um esfôrço notável e até hoje louvado à solicitação que lhe fez o então Ministro da Marinha "impres- 
sionado com as falhas da legislação penal castrense, e com os fatos da indisciplina, que puseram em relêvo a insuficiência dos meios repressivos. CLóVIS, como bom patriota, não recusou o seu auxílio à "obra regeneradora", como êle mesmo o disse. O seu trabalho teve a imponência do seu gênio jurídico, e quem o comparasse com o Código Penal Militar então em vigor, se aperceberia, de pronto, da profundidade da sua contribuição. Trazia acréscimos, supressões e modificações que só um espírito afeito ao estudo científico do direito comparado, poderia adaptar à índole e às necessidades nacionais. Dêle emerge, com clareza solar, o conceito, sempre controvertido, do crime militar, a respeito do qual as nossas leis não ofereceram jamais indicações muito seguras. Antes, já havíamos tido o projeto de 1890 , de que foi relator Carlos de Carvalho, o projeto de João Vieira de Araújo, de 1891, o projeto de Barbosa Lima, de 1900, o de Estevão Lobo de 1905, o de Dunches de Abranches de 1907, o de Cândido Mota, de 1911, e, a seguir ao projeto de CLóVIS, o de Pedro da Cunha Pedrosa, de 1917, o da Comissão nomeada pela Lei 3999, de 5 de janeiro de 1920, da qual foi presidente o Ministro do Supremo Tribunal Militar, Dr. Vicente Neiva e, posteriormente, mais alguns outros, inclusive o de Epitácio Pessoa, relativo à reorganização judiciária militar.

Como se vê, era exaustivo o trabalho dos nossos jurisconsultos, dada a manifesta relevância da matéria.

Em seu Esboço, CLóVIS desviou-se do sistema italiano, que fôra primitivamente adotado pelo legislador pátrio, e dentro do plano que adotou, foi mais técnico e ao mesmo tempo mais sintético, como se coadunava com o seu espírito de clareza e simplicidade, virtudes inatas dos que verdadeiramente sabem.

Assim, ao mesmo tempo que declarava, como objeto do Código, as infrações da lei penal da Armada, manda aplicar ao direito penal militar as disposições do Código Penal comum relativas ao crime, à pena e à reabilitação do criminoso, apenas com as modificações constantes da lei particular, dando, por conseguinte, o domínio da Parte Geral do Código Penal comum sôbre o da Armada. Era um sistema de coerência legislativa a serviço da unidade dos princípios gerais do Direito Penal e da Criminologia, sem distinguir, quanto às 
espécies delituosas, o criminoso comum do criminoso militar, sem esquecer, tão pouco, de separar, nìtidamente, as disposições destinadas ao estado de paz e as destinadas, especialmente, ao estado de guerra. Teve a visão panorâmica, do ponto de vista jurídico, dos dois estados e observou: "na tranqüilidade da paz, as condições do meio social são outras, e as delongas do processo judicial põem considerável distância entre o fato delituoso e a execução da pena. Em época de guerra (e veremos mais adiante o seu conceito da guerra total) em época de guerra, dizia, o meio em que opera o delinqüente é mais estreito, a máquina repressiva funciona mais ràpidamente, encurtando a distância entre o crime e a reação punitiva. A representação do sofrimento legal pode, assim, crear um movimento inhibitório da atividade criminosa. Além disso, a eliminação, pela morte, que, em tempo de paz nenhuma vantagem produz para a sociedade, porque o número dos eliminados seria sempre insignificante em comparação com o número dos que por várias formas se mostram inadaptados à vida social, numa esquadra, em um navio, num corpo de Exército, unidades mais limitadas, a depuração será apreciável. Portanto, se, no primeiro caso, a crueldade legal é inútil, no segundo caso poderá justificar-se por essa aplicação, aliás pouco recomendável, do darwinismo político-jurídico".

Parece que estava escrevendo para os dias de hoje, apresentando, através do dom divinatório da sua vocação jurídica e por fôrça da sua formação rìgidamente liberal, os argumentos destinados a espancar quantos remanescentes por aí proliferam, alguns até injuriando a alma piedosa da nossa educação cristã, disso que já é lugar comum denominar uma reminiscência de barbárie.

E, assim como em 1912 atendia êle, com desvelado carinho, como era do seu feitio moral, à solicitação do govêrno da República, para a elaboração de um Código Penal Militar, em face da sublevação da marinhagem dos mais poderosos vasos da Armada Nacional, episódio que "vinha desnudar a situação de real antinomia entre a legislação criminal e disciplinar da Marinha de Guerra e a Constituição Federal, situação que, se era conhecida nos círculos em que as questões de interêsse nacional se esmerilham com desassombro, pertinácia e dedi- 
cação, como êle mesmo fizera sentir, ainda não tivera oportunidade para ser tão rudemente ostentada aos olhos de todos", com a mesma desambição, com o mesmo civismo, com igual denodo e presteza, haveria de acudir, em 1942, já quase ao apagar de sua vida exemplar e fecunda, à proclamação do então Ministro da Guerra, que sendo dirigida, num momento angustioso da vida nacional, aos Oficiais e Praças do Exército, contudo era, em realidade, um grito de mobilização de todos os brasileiros, quando o afundamento de nossos navios, dentro dos nossos mares territoriais, cobria-nos de luto e sangrava de dor os nossos corações, pondo em perigo a soberania da Nação.

Diante do rude golpe, como escreveu em sua proclamação o Ministro da Guerra, "diante da trágica realidade, diante da ousadia inglória de destruir, à vista de nossas praias, embarcações costeiras que, em despreocupado cruzeiro, ostentavam nos seus mastros a bandeira do Brasil", era, realmente, imperioso que se erguesse o Exército "unido e confiante, disposto, como sempre, a todos os sacrifícios na defesa do nosso grandioso patrimônio moral e material, imperecível legado dos nossos antepassados", mas urgia, também, que em atendimento a êsse apêlo dramático, nenhum filho do Brasil faltasse ao seu dever naquela "hora sombria" que estava a exigir "a união de todos na defesa de nossas tradições e de nossos direitos".

E CLÓVIS não se ausentou do seu dever. A Pátria precisava de todos, nem só dos seus soldados e de todos nós como homens do povo, senão também dos seus homens de pensamento e de saber, e dêle quiçá com mais empenho, como penalista, civilista, constitucionalista, internacionalista, sociólogo, filósofo, erudito, humanista, conselheiro.

Nesse momento exarou êle o seu parecer histórico, por solicitação do Govêrno, sôbre as bases para a revisão, que se fazia urgente, do Código da Justiça Militar, e então, como diz uma das mais eminentes figuras do Direito Penal Militar, Ministro Gomes Carneiro, "respondendo ao questionário em que, pela primeira vez, em matéria de organização judiciária militar e processo penal militar, se puseram em equação todos os problemas jurídicos fundamentais, necessários, CLÓVIS BEVILAQUA, com a elevação moral que aureola a sua obra 
de jurisconsulto e com a clareza e segurança do seu espírito privilegiado, resumiu, nos conselhos dados, a sua opinião a respeito do plano de reforma, considerada inevitável".

$\mathrm{E}$ dêsse questionário, no qual se consubstanciavam dez questões da maior relevância, já no atinente à organização dos tribunais militares e aos graus constitucionais de jurisdição, à organização e prerrogativas do Ministério Público Militar, às atribuições da Corregedoria, como também ao funcionamento da segunda instância no teatro das operações militares, à competência, ao tratamento dos oficiais e praças do serviço ativo nas Polícias Militares da União e dos Estados, destacava-se, principalmente, a questão de definir como atentatórios contra as instituições militares, todos os atos praticados por civis contra a ordem, a segurança, o serviço, a economia e a propriedade das fôrças armadas, para o fim de resguardar o país de todos os perigos e danos, que pode causar o sistema de guerra total.

As respostas de CLóVIS foram modelares, e no que tocava ao sistema de guerra total para a conceituação formal de delitos sôbre êsse estado bélico, reafirmou a sua profissão de fé patriótica e jurídica. Disse êle: "A guerra total é creação anômala da sina dos princípios, com que a civilização tentara submeter, a certas normas, a luta armada entre nações. E a supressão dos imperativos da humanidade e do direito, imposta pela ambição desregrada, pela paixão doentia do mundo, pela inflação do egoísmo, que no tecido das relações sociais, sòmente vê um objetivo: a realização de suas pretensões, sem escolha de meios. Mas é a guerra que no momento atual o totalitarismo implantou. Temos de enfrentá-la, de suportá-la. Assim, sob a pressão das circunstâncias, e tendo em vista a segurança nacional, a defesa do país, em face dos perigos e danos, que pode causar o sistema de guerra total, acho que é permitido, nessa emergência, considerar atentatório das instituições militares os atos praticados por civis contra a ordem, a segurança, o serviço, a economia e a propriedade das fôrças armadas. $\mathbf{E}$ desvio de normas do Direito Internacional, que nos é imposto para a defesa do país, porque a guerra total, embora, às vêzes, invoque o Direito Internacional, desenvolve-se fora dêle. Velho jurista, constrangeme aceitar essa anomalia. Mas não aceitá-la, deante da guer- 
ra total, é debilitar a defesa da Pátria. Será uma situação excepcional e transitória, medida de ocasião, que não creará precedente. Tenho inabalável convicção de que voltaremos ao regime do Direito e de que a reconstrução do mundo, depois da guerra, assentará em bases que firmarão a Paz e a Justiça".

Nada é possível de mais lapidar do que isso na palavra de um jurista. E essa palavra, saída da bôca de CLóVIS, vem inspirada pelo mais puro pensamento. Talvez mais do que isso, por um sentido verdadeiramente sublime. Ela vale como o prenúncio de uma nova Renascença. Dessa Renascença pela qual todos devemos lutar, dentro de um mundo inteiramente livre, porque é a Renascença espiritual da grandeza humana, garantida pela Paz e pela Justiça.

E ela foi anunciada pela crença profética do jurista-filósofo, a se confessar na fé irremovível do império do Direito.

Realmente, CLÓVIS foi um santo. Mas sobretudo bom. Sobretudo sábio. Glória, pois, à sua memória. 